\title{
Targeted rotavirus vaccination of high-risk infants; a low cost and highly cost-effective alternative to universal vaccination
}

Patricia Bruijning-Verhagen ${ }^{1 *}$, Marie-Josée J Mangen ${ }^{1}$, Mariet Felderhof ${ }^{2}$, Nico G Hartwig ${ }^{3}$, Marlies van Houten², Léon Winkel ${ }^{4}$, Wouter J de Waal ${ }^{5}$ and Marc JM Bonten ${ }^{1}$

\begin{abstract}
Background: The cost-effectiveness of universal rotavirus (RV) vaccination is controversial in developed countries. As a result, RV vaccination programs do not currently exist in most European countries. Hospitalization is the main driver of RV disease costs, and prematurity, low birth weight (LBW) and underlying medical conditions have been associated with RV hospitalization and complications. We investigated the cost-effectiveness of targeted RV vaccination of high-risk infants and universal RV vaccination versus no vaccination.

Methods: Disease burden, mortality and healthcare costs of RV hospitalization for children with and without prematurity, LBW and congenital pathology were quantified in two hospital-based observational studies in the Netherlands. Cost-effectiveness analysis was based on an age-structured stochastic multi-cohort model of the Dutch population comparing universal RV vaccination and targeted vaccination of high-risk infants to no vaccination. The primary endpoint was the incremental cost-effectiveness ratio (ICER), with a threshold of $€ 35,000 /$ quality-adjusted life year (QALY) from the healthcare provider perspective. Sensitivity analyses included vaccine price and coverage, herd-immunity and QALY losses.

Results: A total of 936 children with RV infection were included. Prematurity, LBW and congenital pathology were associated with increased risks of RV hospitalization (relative risks (RR) ranging from 1.6 to 4.4), ICU admission (RR ranging from 4.2 to 7.9 ), prolonged hospital stay (1.5 to 3.0 excess days) and higher healthcare costs (€648 to $€ 1,533$ excess costs). Seven children succumbed due to RV complications, all belonging to the high-risk population. Targeted RV vaccination was highly cost-effective and potentially cost-saving from the healthcare provider perspective with ICERs below $€ 20,000 /$ QALY in all scenarios with total (undiscounted) annual healthcare costs between - $€ 0.1$ and $€ 0.5$ million/year. Results were most sensitive to mortality rates, but targeted vaccination remained highly cost-effective up to reductions of $90 \%$ compared to observed mortality. Universal RV vaccination was not considered cost-effective (mean ICER: €60,200/QALY) unless herd-immunity and caretaker QALY losses were included and vaccine prices were $€ 60$ at most (mean ICER: $€ 21,309 /$ QALY).
\end{abstract}

Conclusion: We recommend targeted RV vaccination for high-risk infants in developed countries.

Keywords: Rotavirus vaccination, Cost-effectiveness, Cost-utility, High-risk population, Targeted prevention, Hospitalization, Nosocomial infection, Mortality

\footnotetext{
* Correspondence: P.Bruijning@umcutrecht.nl

'Julius Center for Health Sciences and Primary Care, University Medical

Center Utrecht, Huispostnummer STR.6.131, Postbus 85500, Utrecht 3508 GA,

The Netherlands

Full list of author information is available at the end of the article
} 


\section{Background}

Rotavirus (RV) vaccination reduces severe RV gastroenteritis (GE), associated healthcare utilization and mortality among young children $[1,2]$. Universal infant vaccination with either the monovalent life-attenuated vaccine (RV1) or the pentavalent human-bovine reassortant vaccine (RV5) has, therefore, been recommended by professional healthcare organizations worldwide [3-7] but results of cost-effectiveness analyses of RV vaccination in developed countries yielded conflicting results [8-11]. Consequently, $R V$ vaccination programs have been introduced in only a very limited number of European countries [12].

Although RV is widely considered a universal pediatric infection with young age as the only important risk factor, in the developed world hospitalization due to RV, the main driver of RV associated healthcare costs, seems to be associated with underlying chronic disease, congenital disorders, prematurity and low-birth weight (LBW) [13-24]. Moreover, these children are more prone to complicated RV disease courses with more frequent ICU admission [18]. RV infection in premature or LBW infants has been associated with necrotizing enterocolitis, encephalopathy [25-29] and increased diarrheal mortality [30-32].

A targeted vaccination strategy for RV, in which vaccination is offered to high-risk infants only, has not been economically evaluated thus far. We, therefore, set out to determine the cost-effectiveness of such an approach in the Netherlands, where universal RV vaccination has not been implemented yet, similar to the situation in most European countries. We first quantified RV related hospitalizations in the Netherlands and identified patient groups at increased risk of RV hospitalization or with increased healthcare needs when hospitalized. Subsequently, these data were supplemented with relevant available epidemiological data to determine cost-effectiveness of both universal and targeted $\mathrm{RV}$ vaccination strategies compared to no vaccination from a healthcare provider perspective.

\section{Methods}

\section{Rotavirus hospitalizations; observational study}

The methodology of this study has been described elsewhere [33]. In brief, laboratory confirmed RV related pediatric hospitalizations occurring in four participating hospitals (three general hospitals, one tertiary care center) during a five-year period (December 2005 to November 2010) were retrospectively studied. RV underreporting was subsequently assessed by hospital-based active surveillance during the $2011 \mathrm{RV}$ season in the same four hospitals [33].

A comprehensive chart review was performed for each case extracting data on RV disease course, healthcare resource utilization and patient's medical history to identify conditions potentially associated with increased clinical vulnerability, such as prematurity of $<36$ weeks gestational age and/or LBW ( $<2,500$ grams) and complex chronic conditions. Complex chronic conditions were those that (1) are expected to last longer than 12 months and (2) involve either several different organ systems or one organ system severely enough to require specialty pediatric care and hospitalization. This classification characterizes a group of patients with increased healthcare needs and mortality [34-36]. We further classified complex chronic conditions into those with a congenital origin (that is, severe congenital pathology) and those with onset later in life.

Prevalence rates for prematurity/LBW and severe congenital pathology were also derived for the Dutch infant population from national disease and birth registries, covering $96 \%$ of the Dutch infant population [37,38]. In addition, a nested case-control study was performed to investigate if the same conditions increased the risk of nosocomial RVGE compared to otherwise healthy age-matched hospital controls [see details in Additional file 1].

Healthcare resource utilization, assessed at the individual patient level, was used for cost calculations, adapting standard cost prices and charges [see Additional file 1: Table S1] $[39,40]$. Costs included hospitalization days, preceding emergency department visits, contact isolation precautions [41] and ambulance transportation. For nosocomial RVGE costs for RV related excess hospitalization days were used [33], or, when hospitalization was not prolonged, isolation costs and RVGE related diagnostic and therapeutic costs. This study was approved by institutional review board of the University Medical Centre Utrecht.

\section{Statistical analysis}

The prevalence of prematurity/LBW and severe congenital pathology among RV hospitalizations compared to the general infant population were used to compute Risk Ratios (RR). To account for the clustered study design and for oversampling of tertiary-care hospitalizations compared to their national share in pediatric hospitalizations (20\%), weighted prevalence estimates were calculated with variance estimated using Taylor series linearization [42].

Rates of ICU admission and RV-related deaths were compared between RV patients with and without potential high-risk conditions by computing RR. Length of stay or excess hospitalization days in the case of nosocomial RVGE and healthcare costs were compared by t-test, using the arithmetic mean despite the usually skewed distribution. The arithmetic mean is considered most informative in evaluations designed to have an impact on medical policy, because it is the total disease burden that is important [43].

Any of the assessed risk factors (prematurity/LBW or congenital pathology) that were associated with increased risk of RV hospitalization, nosocomial RVGE, RV-related death and/or increased length of stay were included to determine eligibility for targeted vaccination, excluding those 
who suffered from severe immunodeficiencies, in whom $R V$ vaccination is contra-indicated [44].

Differential RV hospitalization rates were calculated for eligible and ineligible children from RVGE numbers adjusted for underreporting using weighted estimation [42]. Similarly, weighted mean hospitalization costs for community-acquired and nosocomial RV infections were calculated among eligible and ineligible children.

Analyses were performed using $\mathrm{R}$ software, version 1.14.1.

\section{Model design}

We used an age-structured, discrete time-event, stochastic multi-cohort model of the Dutch population, as previously described by Mangen et al. [45] to investigate the cost-effectiveness of adding RV vaccination to the Dutch infant immunization program under two scenarios: (1) universal vaccination and (2) targeted vaccination of high-risk infants.

Strategies were compared assuming an annual birth cohort of 180,000 infants, equivalent to the 2010 Dutch birth cohort. The effect of vaccination was modeled as a reduction in RVGE and associated health outcomes in vaccinated compared to non-vaccinated children between 0 and 15 years old with RV disease risk stratified by age and time since vaccination [see Additional file 1: Figure S1]. Time steps of one month were used for ages 0 to 11 months and of one year thereafter. Effects were modeled over a time-horizon of 20 years with year one being the start of either vaccination program. The model was adapted to simulate targeted vaccination by splitting the population into a vaccination eligible and an ineligible fraction. We assumed no effect on adult RV infections from any of the infant vaccination strategies.

\section{Model parameters}

Estimates of RV infection rates, outpatient healthcare visits and related direct and indirect healthcare costs for different age-groups were derived from existing epidemiological sources as previously described by Mangen et al. (Table 1) [45]. Hospitalization rates and costs for children eligible and ineligible for targeted vaccination and for combined groups were derived from our multi-center observational study.

Mortality due to RV was determined by combining data from the multi-center observational study and from another study in a Dutch tertiary-care hospital. In this study RV-related mortality was determined for all children who had died within three weeks of confirmed RV infection between 2000 and 2006. Conservative estimates were used for national mortality figures, assuming that fatal cases exclusively occurred among RV hospitalizations at tertiary-care centers without underreporting.
An expert panel of four pediatricians was consulted to determine years of life lost (YLL) accountable to RV infection among observed fatal cases (Table 1). This approach was used to take into account the reduced life expectancy in children with complex chronic conditions.

We used Quality Adjusted Life Years (QALYs), the product of the health-state utility and the length of time in that state, to weigh losses as a result of RV episodes requiring different levels of healthcare, similar to those used in previous cost-effectiveness analyses $[9,10,45]$. QALY losses due to RV mortality were based on YLL estimates for observed fatal RV cases.

European vaccine efficacy data were used for agespecific vaccination effects (Table 2) [53-56,63]. Linear waning immunity was assumed for the third, fourth and fifth year post-vaccination, and zero protection thereafter. Rotavirus genotype distribution in the Netherlands is comparable to the observed genotype distribution in European vaccine efficacy trials. Overall, G1P [8] is the dominant strain and G2P [4], G3P [8], G4P [8] and G9P [8] are common co-circulating strains with year-to-year variability in strain distribution [52]. We assumed $88 \%$ adherence to vaccination recommendations for both universal and targeted RV vaccination, the observed current vaccine coverage in neighboring Belgium where universal RV vaccination was implemented in 2007 [64], and used coverage rates from $65 \%$ to $97 \%$ in sensitivity analysis.

Vaccine costs for universal RV vaccination were based on Rozenbaum et al. who assumed that tender processes lower vaccine prices by almost $50 \%$ ( $€ 75$ per vaccine course) compared to the current free market price [10]. Targeted vaccination was assumed to generate price reductions of $25 \%$ ( $€ 100$ per vaccine course). We also included scenarios with the free market price for both vaccination strategies. We assumed vaccine doses would be administered during routine immunization clinic visits at a standard application fee of $€ 6.44$ per vaccination [45].

Indirect vaccination effects (herd-immunity) among unvaccinated children were considered as part of the sensitivity analysis (Table 1) [58-60]. No herd-immunity was assumed in the case of targeted vaccination, as vaccine coverage was considered too low for herdimmunity to occur.

\section{Cost-effectiveness analysis}

Our primary perspective was that of the healthcare provider and a societal perspective was included in sensitivity analysis taking non-healthcare costs into account, updated from Mangen et al. with additional data on parental work loss due to RV hospitalizations in children [65]. All costs were converted to 2011 Euros. A 3\% discount rate for costs and benefits was used in base-case scenarios according to World Health Organization (WHO) guidelines [66]. Other 
Table 1 Parameters for model input

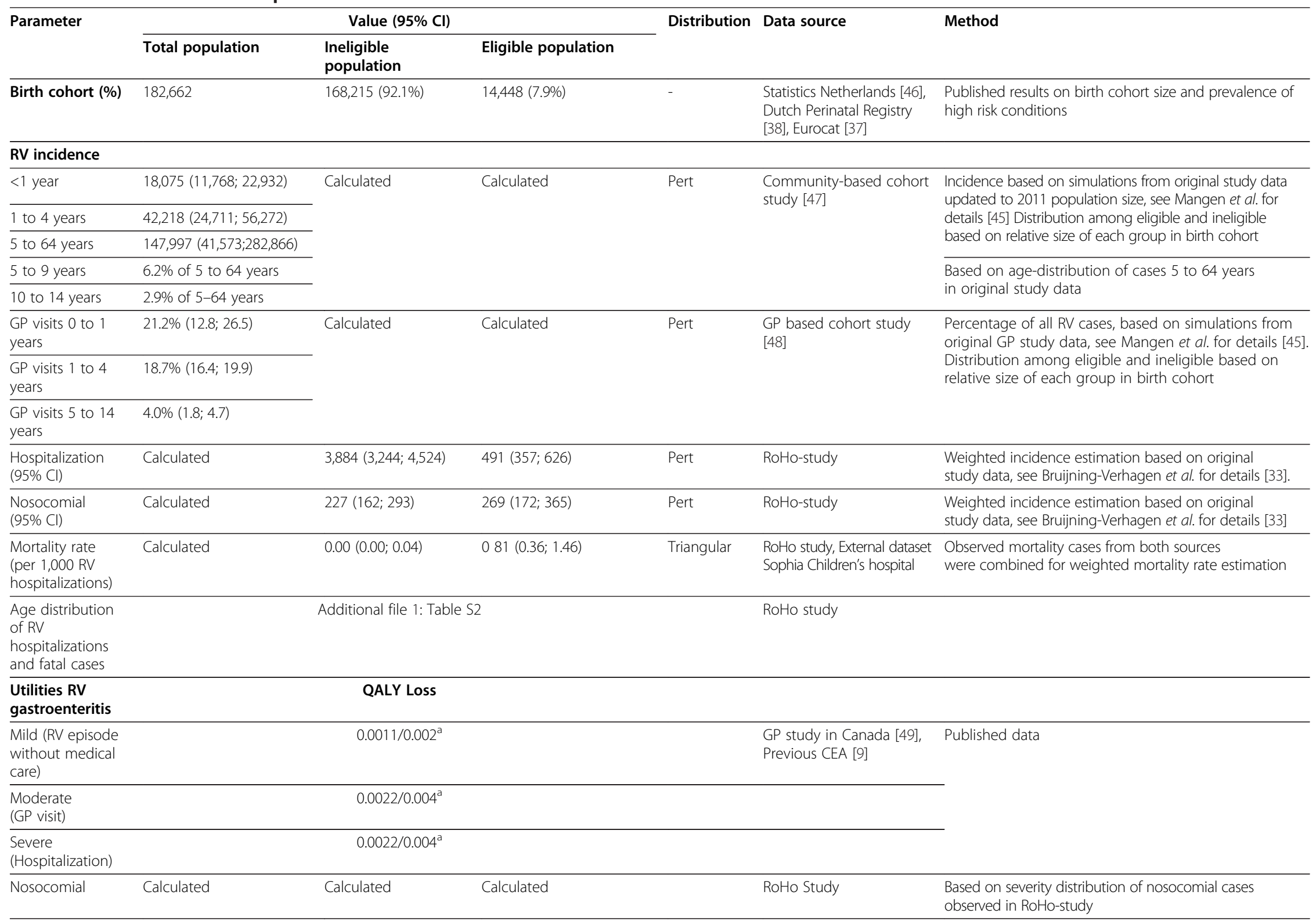


Table 1 Parameters for model input (Continued)

\begin{tabular}{|c|c|c|c|c|c|c|}
\hline \multirow[t]{2}{*}{ Parameter } & \multicolumn{3}{|c|}{ Value $(95 \% \mathrm{Cl})$} & \multirow[t]{2}{*}{ Distribution } & \multirow[t]{2}{*}{ Data source } & \multirow[t]{2}{*}{ Method } \\
\hline & Total population & $\begin{array}{l}\text { Ineligible } \\
\text { population }\end{array}$ & Eligible population & & & \\
\hline Mortality & Calculated & $\begin{array}{l}80.7 \text { minus } \\
\text { patient's age }\end{array}$ & 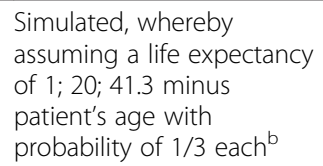 & Uniform & $\begin{array}{l}\text { Statistics Netherlands [46], } \\
\text { Expert opinion }\end{array}$ & $\begin{array}{l}\text { For ineligible: Based on average life expectancy in the } \\
\text { Netherlands. For eligible: Based on expert panelt }\end{array}$ \\
\hline \multicolumn{7}{|l|}{$\begin{array}{l}\text { Direct healthcare } \\
\text { costs (Euro) }\end{array}$} \\
\hline $\begin{array}{l}\text { Gastroenteritis } \\
\text { episodes without } \\
\text { medical care }\end{array}$ & \multicolumn{3}{|c|}{0} & \multirow[t]{6}{*}{ Fixed } & & \\
\hline Standard GP visits & \multicolumn{3}{|c|}{29} & & \multirow{3}{*}{$\begin{array}{l}\text { Guidelines for health- } \\
\text { economic evaluations [39] }\end{array}$} & \multirow{3}{*}{$\begin{array}{l}\text { Standard Cost Prices. See Mangen et al. for } \\
\text { details }[45]\end{array}$} \\
\hline Home visit GP & \multicolumn{3}{|c|}{45} & & & \\
\hline $\begin{array}{l}\text { GP consultation } \\
\text { by phone }\end{array}$ & \multicolumn{3}{|c|}{15} & & & \\
\hline Prescriptions & \multicolumn{3}{|c|}{40} & & \multirow{2}{*}{$\begin{array}{l}\text { Community-based cohort } \\
\text { study and GP based } \\
\text { cohort study }[49,50]\end{array}$} & \multirow[t]{2}{*}{ See Mangen et al. [45] } \\
\hline Laboratory costs & \multicolumn{3}{|c|}{73} & & & \\
\hline Hospitalization & Calculated & $2,179(2,027 ; 2,330)$ & $2,550(2,508 ; 3,606)$ & Pert & RoHo study & $\begin{array}{l}\text { Weighted estimates from original study data, } \\
\text { see Additional file } 1\end{array}$ \\
\hline Nosocomial & Calculated & $1,995(1,242 ; 2,748)$ & $2,129(1,203 ; 3,055)$ & & & \\
\hline \multicolumn{7}{|l|}{$\begin{array}{l}\text { Direct non- } \\
\text { healthcare costs }\end{array}$} \\
\hline $\begin{array}{l}\text { RV episode } \\
\text { without medical } \\
\text { care }\end{array}$ & \multicolumn{3}{|c|}{ Additional diapers } & Uniform & Assumption & \multirow[t]{4}{*}{ See Mangen et al. [45] } \\
\hline GP visits & & tional diapers and tray & costs & & $\begin{array}{l}\text { Guidelines for health- } \\
\text { economic evaluations [39] }\end{array}$ & \\
\hline Hospitalization & \multirow{2}{*}{\multicolumn{3}{|c|}{ Travel costs }} & Pert & & \\
\hline Nosocomial & & & & & & \\
\hline \multicolumn{7}{|l|}{$\begin{array}{l}\text { Indirect non- } \\
\text { healthcare costs }\end{array}$} \\
\hline $\begin{array}{l}\text { Costs per hour } \\
\text { work loss (euro) }\end{array}$ & & 31.11 & & Fixed & $\begin{array}{l}\text { Statistics Netherlands [48] } \\
\text { Guidelines for health- } \\
\text { economic evaluations [39] }\end{array}$ & See Mangen et al. [45] \\
\hline $\begin{array}{l}\text { Hours of work loss } \\
\text { for RV episode } \\
\text { without medical } \\
\text { care }\end{array}$ & \multicolumn{3}{|c|}{$0.93 ; 1.36 ; 0.84$ for ages 0 to $4 ; 5$ to 9 and 10 to 14 years respectively } & Uniform & $\begin{array}{l}\text { Community-based cohort } \\
\text { study and GP based } \\
\text { cohort study }[49,50]\end{array}$ & Dependent of patient-age. See Mangen et al. [45] \\
\hline $\begin{array}{l}\text { Hours of work loss } \\
\text { GP visits }\end{array}$ & \multicolumn{3}{|c|}{$1.35 ; 1.98 ; 1.23$ for ages 0 to $4 ; 5$ to 9 and 10 to 14 years respectively } & Uniform & & \\
\hline
\end{tabular}

Community-based cohort See Mangen et al. [45] cohort study $[49,50]$ 
Table 1 Parameters for model input (Continued)

\begin{tabular}{|c|c|c|c|c|c|c|}
\hline \multirow[t]{2}{*}{ Parameter } & \multicolumn{3}{|c|}{ Value $(95 \% \mathrm{Cl})$} & \multirow[t]{2}{*}{ Distribution } & \multirow[t]{2}{*}{ Data source } & \multirow[t]{2}{*}{ Method } \\
\hline & Total population & $\begin{array}{l}\text { Ineligible } \\
\text { population }\end{array}$ & Eligible population & & & \\
\hline $\begin{array}{l}\text { Hours of work loss } \\
\text { Hospitalization }\end{array}$ & \multicolumn{3}{|c|}{37.32} & & \multirow[t]{2}{*}{$\begin{array}{l}\text { hospital based } \\
\text { observational study [51] }\end{array}$} & $\begin{array}{l}\text { Based on the findings from Friesema et al. [52] } \\
\text { for children up to 18, Further details see } \\
\text { Mangen et al. [45] }\end{array}$ \\
\hline $\begin{array}{l}\text { Hours of work loss } \\
\text { Nosocomial }\end{array}$ & & 24.58 & & & & $\begin{array}{l}\text { Based on the findings from Friesema et al. [52] } \\
\text { for children up to } 18 \text {, adjusted for excess duration of } \\
\text { hospitalization among nosocomial in RoHo study } \\
\text { (2.7 versus } 2.9 \text { days) }\end{array}$ \\
\hline Vaccine efficacy & & Table 2 & & & Vaccine trials [53-57] & \\
\hline \multirow[t]{2}{*}{ Herd-immunity } & $\begin{array}{l}\text { Universal RV } \\
\text { vaccination }\end{array}$ & \multicolumn{2}{|c|}{ Targeted RV vaccination } & & & \\
\hline & $30 \%$ (0\% to $46 \%)$ & - & & Triangular & $\begin{array}{l}\text { Observational studies } \\
\text { from US [58,59], Australia } \\
\text { [60,61], Belgium [62] }\end{array}$ & Published data \\
\hline \multicolumn{7}{|l|}{ Vaccination costs } \\
\hline RV1 & $60 ; 75 ; 90$ & & $80 ; 100 ; 120$ & & \multirow{2}{*}{$\begin{array}{l}\text { Previous CEA [10] For } \\
\text { Eligible: Assumption }\end{array}$} & \multirow[t]{2}{*}{ Assumed tender Price } \\
\hline RV5 & $60 ; 75 ; 90$ & & $80 ; 100 ; 120$ & & & \\
\hline $\begin{array}{l}\text { Startup costs } \\
\text { first year }\end{array}$ & 218,440 & - & & & & \\
\hline $\begin{array}{l}\text { Application } \\
\text { costs }\end{array}$ & \multicolumn{3}{|l|}{6.44} & & & \multirow[t]{2}{*}{ See Mangen et al. [45] } \\
\hline $\begin{array}{l}\text { Administration } \\
\text { costs }\end{array}$ & \multicolumn{3}{|l|}{1.64} & & & \\
\hline
\end{tabular}

\section{accination costs}




\section{Table $\mathbf{2}$ Vaccine efficacy estimates against mild, moderate and severe RV gastroenteritis}

\begin{tabular}{|c|c|c|c|c|c|c|}
\hline \multicolumn{5}{|c|}{ Vaccine efficacy ${ }^{a}$} & \multirow[t]{2}{*}{ Method } & \multirow[t]{2}{*}{ Source } \\
\hline RV1 & $\begin{array}{l}\text { Mild (RV episode } \\
\text { without medical care) }\end{array}$ & $\begin{array}{l}\text { Moderate } \\
\text { (GP visit) }\end{array}$ & $\begin{array}{l}\text { Severe } \\
\text { (Hospitalization) }^{\mathrm{b}}\end{array}$ & Nosocomial $^{c}$ & & \\
\hline After first dose & Calculated & Calculated & $89.8 \%(8.9$ to 99.8$)$ & \multirow[t]{4}{*}{ Calculated } & \multirow{3}{*}{$\begin{array}{l}\text { (Calculated from) Published data } \\
\text { Efficacy for mild and moderate cases after first season calculated } \\
\text { from efficacy ratios for mild, moderate, severe during first season }\end{array}$} & \multirow[t]{3}{*}{ [53] } \\
\hline $\begin{array}{l}\text { First season } \\
\text { (after second dose) }\end{array}$ & $71.7 \%(50.4$ to 83.9$)$ & $91.8 \%$ (84.0 to 96.3$)$ & $100 \%$ (81.8 to 100$)$ & & & \\
\hline Second season & $50.5 \%(24.3$ to 67.7$)$ & $76.2 \%(63.0$ to 85.0$)$ & $92.2 \%(65.6$ to 99.1$)$ & & & \\
\hline Third-fifth season & Calculated & Calculated & Calculated & & $\begin{array}{l}\text { Efficacy during third to fifth season calculated as linear } \\
\text { decline equal to reduction between first and second season }\end{array}$ & \\
\hline \multicolumn{7}{|l|}{ RV5 } \\
\hline After first dose & Calculated & Calculated & $88 \%$ (65 to 97$)$ & \multirow[t]{6}{*}{ Calculated } & (Calculated from) Published data Efficacy after first dose and & \multirow[t]{2}{*}{ [57] } \\
\hline After second dose & Calculated & Calculated & $88 \%$ (69 to 96$)$ & & $\begin{array}{l}\text { between first and second dose for mild and moderate cases } \\
\text { calculated from efficacy ratios for mild, moderate, severe } \\
\text { during first season }\end{array}$ & \\
\hline $\begin{array}{l}\text { First season } \\
\text { (after third dose) }\end{array}$ & $65.1 \%(54.1$ to 73.5$)$ & $72.0 \%(63.2$ to 78.9$)$ & $94.8 \%(89.4$ to 97.8$)$ & & (Calculated from) Published data & {$[54,55]$} \\
\hline Second season & $49.8 \%$ (27.0 to 65.4$)$ & $58.5 \%(40.1$ to 71.7$)$ & $90.8 \%$ (76.9 to 97.1) & & & \\
\hline Third season & Calculated & Calculated & $100.0 \%(27.9$ to 100$)$ & & $\begin{array}{l}\text { Efficacy during third season for mild and moderate cases } \\
\text { calculated from efficacy ratios for mild, moderate, severe } \\
\text { during second season }\end{array}$ & {$[55]$} \\
\hline Fourth-fifth season & Calculated & Calculated & Calculated & & $\begin{array}{l}\text { Efficacy during third to fifth season calculated as linear decline } \\
\text { equal to reduction between first and second season }\end{array}$ & \\
\hline
\end{tabular}

$\bar{a}$ Vaccine efficacy was assumed equal between eligible and ineligible, data were modeled as Pert distribution; ${ }^{b}$ efficacy against fatal RVGE was assumed equal to efficacy for severe disease; ${ }^{c}$ efficacy against nosocomial infection based on severity distribution in original study data.

GE: gastroenteritis; GP: general practitioner; RV: rotavirus. 
discount rates, including those recommended for Dutch health economic evaluations, were used in sensitivity analysis [39]. Although there is no consensus on a cut-off point for good value for resources, we present our results in the context of commonly cited thresholds per QALY of $\$ 50,000$ equivalent to $€ 35,000[67,68]$. This amount is approximately equal to the Dutch Gross Domestic Product per capita in 2011, the recommended threshold for highly cost-effective interventions by the WHO [66]. In addition, we used the unofficial threshold of $€ 20,000 / \mathrm{Q} A L Y$ commonly applied in the Netherlands for preventive healthcare interventions.

Total net healthcare costs for either vaccination strategy compared to no vaccination are reported (cost-analysis) as well as incremental cost-effectiveness ratios (ICERs), representing costs per QALY gained comparing either strategy with no vaccination. Strategies were considered costeffective if they generated ICER's less than a willingness-to -pay threshold of $€ 35,000 / \mathrm{QALY}$ from the healthcare provider perspective. An ICER below $€ 20,000 / Q A L Y$ was considered highly cost-effective. As additional scenario analysis, we also calculated incremental costs and QALY's gained for universal RV vaccination compared to targeted vaccination.

The simulation model was built in Microsoft Excel using add-in software @Risk, version 5.5 (Palisade). Results are presented as means and 95\% confidence interval (CI) of simulated results, based on 10,000 iterations. Parameters were varied simultaneously in probabilistic sensitivity analyses, performing random draws from distributions. Distributions were chosen based on parameter characteristics and level of certainty. Input parameters and their distributions with corresponding information source are presented in Table 1. In addition, we performed one-way sensitivity analysis to determine variables which were most influential on model results.

\section{Results}

\section{Rotavirus hospitalizations; observational study}

Overall, 944 RV infections were identified. After excluding six patients with asymptomatic disease and two without medical records available, 936 patients were analyzed. RVGE was community-acquired and nosocomial in $770(81 \%)$ and $176(19 \%)$ episodes, respectively [see Additional file 1: Table S4].

In 134 patients (14\%) RVGE occurred before 15 weeks of age and would not be prevented by vaccination, unless by herd-immunity. Prevalence of prematurity $<36$ weeks was $9 \%(\mathrm{n}=83)$, of low birth weight was $11 \%(\mathrm{n}=104)$ and of complex chronic conditions at the time of RV infection was $23 \%(n=219)$. The latter was more frequent among nosocomial than among community-acquired infections $(64 \%$ versus $14 \%, P<0.0001)$. Most of these patients $(\mathrm{n}=116$, $53 \%$ ) suffered from severe congenital pathology. Based on weighted prevalence of prematurity, LBW and congenital pathology among RV hospitalizations and the general infant population, all three conditions were significantly more common among children hospitalized for RVGE and were, therefore, classified as high-risk for RV hospitalization (mean RR: 1.7; 1.6; 4.4, respectively; Table 3). RVGE-related ICU admission occurred more frequently among children with prematurity, LBW and congenital pathology than among otherwise healthy patients (mean RR ranging from 4.2 to 7.9). Mean length of stay was increased by 1.5 to 3.0 days and mean healthcare costs were $€ 648$ to $€ 1,533$ per patient higher (Table 3). Results from the nested matched case-control study demonstrated increased risks of acquiring nosocomial RVGE for prematurity (aOR: 3.3, 95\% CI: 1.5 to 7.3 ), LBW (aOR: 3.2, 95\% CI: 1.5 to 7.1) and congenital pathology (aOR: 3.6, 95\% CI: 1.8 to 7.0 ) compared to healthy hospitalized controls (details in Additional file 1).

\section{RV mortality}

Two RV related fatalities were observed in the multicenter study and an additional five among 214 confirmed RVGE episodes over six years in the second observational study at a different tertiary care center. All seven had congenital pathology and two patients also had a history of LBW. One child died before 2 months of age, the remaining six children died between 2 and 14 months of age.

\section{RV epidemiology and vaccination effects}

Without vaccination, there were an estimated 75,000 (95\% CI: 58,000 to 90,000) RVGE episodes annually, with 4,870 ( $95 \%$ CI: 4,310 to 5,430 ) hospitalizations including 500 nosocomial infections among children 0 to 15 years old, generating $€ 11.9$ (95\% CI: 10.5 to 13.3 ) million in total healthcare costs and $€ 18.2$ million (95\% CI: 16.2 to 20.3) when societal costs are included (Table 4). An estimated 6.5 children (95\% CI: 3 to 11) die prematurely due to RV each year in the Netherlands. A total of 257 QALY's (95\% CI: 136 to 422) are lost due to RV, of which 170 (95\% CI: 50 to 330 ) are due to fatal RV cases.

A universal RV vaccination program (at $€ 75$ per vaccine course per child) generates $€ 15.2$ million in healthcare costs annually when the two-dosage RV1 and $€ 16.7$ million when the three-dosage RV5 is used. The difference is explained by the additional application costs of a third RV5 dose. A total of 3,500 (95\% CI: 3,050 to 3,960) and 3,430 (95\% CI: 2,980 to 3,880) RV hospitalizations are avoided by RV1 and RV5, respectively. QALY's gained mount to 194 (95\% CI: 83 to 348) for RV1 and 188 (95\% CI: 80 to 342 ) for RV5. On average, 6.1 (95\% CI: 3.0 to 10.2) fatal cases are avoided.

Using targeted vaccination, approximately $8 \%$ of the infant population would be eligible for vaccination (that is, children with one or more high-risk conditions). At $€ 100$ per vaccinated child, annual vaccination costs are $€ 1.5$ 
Table 3 Prevalence of high risk conditions among RV hospitalizations and their association with disease outcome and healthcare utilization

\begin{tabular}{|c|c|c|c|c|c|c|c|c|}
\hline \multirow[b]{3}{*}{ High Risk Conditions } & \multicolumn{6}{|c|}{ Prevalence } & \multirow[t]{3}{*}{$P$-value ${ }^{b}$} & \multirow[t]{3}{*}{$\mathrm{RR}^{\mathrm{b}}$} \\
\hline & \multicolumn{2}{|c|}{ Observational study } & \multicolumn{2}{|c|}{$\begin{array}{c}\text { Weighted estimates national RV } \\
\text { hospitalizations }(95 \% \mathrm{Cl})\end{array}$} & \multicolumn{2}{|c|}{ General infant population $^{a}$} & & \\
\hline & $\%$ & $\mathbf{N}$ & $\%$ & $\mathrm{~N}$ & $\%$ & $\mathbf{N}$ & & \\
\hline $\mathrm{GA}<36$ weeks & 8.9 & 83 & $6.8(5.1 ; 8.5)$ & $347(243 ; 451)$ & 4.3 & 7617 & 0.005 & $1.7(1.2 ; 2.8)$ \\
\hline LBW & 11.1 & 104 & $8.8(6.6 ; 11.1)$ & $462(309 ; 615)$ & 6.0 & 10545 & 0.014 & $1.6(1.1 ; 2.3)$ \\
\hline \multirow[t]{3}{*}{ Congenital pathology } & 12.4 & 116 & $6.2(4.9 ; 7.4)$ & $309(244 ; 374)$ & 1.5 & 2719 & $<0.0001$ & $4.4(3.4 ; 5.4)$ \\
\hline & \multirow{2}{*}{\multicolumn{2}{|c|}{ Healthy $(\mathrm{N}=657)$}} & \multicolumn{6}{|c|}{ High risk conditions } \\
\hline & & & \multicolumn{2}{|c|}{ GA <36 weeks $(\mathrm{N}=83)$} & \multicolumn{2}{|c|}{ LBW $(\mathrm{N}=104)$} & \multicolumn{2}{|c|}{ Congenital pathology $(\mathrm{N}=116)$} \\
\hline Outcome and healthcare utilization & $\mathrm{N}(\%)$ & & $\mathrm{N}(\%)$ & RR $(95 \% \mathrm{Cl})$ & $\mathrm{N}(\%)$ & RR $(95 \% \mathrm{Cl})$ & $\mathrm{N}(\%)$ & $\mathrm{RR}(95 \% \mathrm{Cl})$ \\
\hline ICU admission & $4(0.6 \%)$ & & $4(4.8 \%)$ & $7.9(2.0 ; 31.1)$ & $3(2.9 \%)$ & $4.7(1.1 ; 20.9)$ & $3(2.6 \%)$ & $4.2(1.0 ; 18.7)$ \\
\hline \multirow[t]{2}{*}{ RV related death (number,\%) } & 0 & & 0 & & 0 & & $2(1.7 \%)$ & NA \\
\hline & & & & Mean difference $(95 \% \mathrm{Cl})$ & & Mean difference $(95 \% \mathrm{Cl})$ & & Mean difference $(95 \% \mathrm{Cl})$ \\
\hline LOS (mean, SD) & $3.6(2.1)$ & & $5.2(4.7)$ & $+1.6(0.1 ; 3.0)$ & $5.1(4.5)$ & $+1.5(0.3 ; 2.7)$ & $6.6(4.2)$ & $+3.0(1.9 ; 4.1)$ \\
\hline Healthcare costs (mean, SD) & $2,203(2,113)$ & & $3,001(3,407)$ & $+798(28 ; 1,568)$ & $2,851(3,206)$ & $+648(-2 ; 1,297)$ & $3,737(3,500)$ & $+1,533(867 ; 2,199)$ \\
\hline
\end{tabular}

${ }^{\mathrm{a} D u t c h}$ birth cohort alive after one month, $2005-2008^{38}$; ${ }^{\mathrm{b}}$ Comparing weighted RV hospitalizations prevalence to population prevalence.

GA: gestational age; LBW: low birth weight; LOS, length of stay; RR, relative risk; RV, rotavirus; SD: standard deviation.

The figures in bold indicate the results of calculations form other columns in the table and represent the main findings. 
Table 4 Annual results of universal and targeted RV vaccination compared to no vaccination under base-case assumptions

RV disease burden $(95 \% \mathrm{Cl})^{\mathrm{a}}$

\begin{tabular}{|c|c|c|c|c|c|c|c|}
\hline & & & \multirow{2}{*}{$\frac{(€ \text { million) }}{\text { (undiscounted) }}$} \\
\hline & Disease episodes (x1000) & Hospitalizations $^{\mathbf{b}}$ & Fatal cases & QALY's lost (undiscounted) & $\begin{array}{l}\text { Direct healthcare costs } \\
\text { (undiscounted) }\end{array}$ & $\begin{array}{l}\text { Societal costs } \\
\text { (undiscounted) }\end{array}$ & \\
\hline No vaccination & $74.1(57.8 ; 90.0)$ & $4,870(4,310 ; 5,430)$ & $6.5(3.2 ; 11.0)$ & $257(136 ; 422)$ & $11.9(10.5 ; 13.3)$ & $18.2(16.2 ; 20.3)$ & - \\
\hline \multicolumn{8}{|c|}{ Targeted RV vaccination } \\
\hline RV1 & $67.3(51.3 ; 82.4)$ & $4,370(3,890 ; 4,870)$ & $0.7(0.2 ; 1.6)$ & $119(79 ; 177)$ & $10.5(9.3 ; 11.8)$ & $16.4(14.6 ; 18.2)$ & 1.5 \\
\hline Percent reduction & $8 \%$ & $10 \%$ & $89 \%$ & $54 \%$ & $12 \%$ & $10 \%$ & \\
\hline RV5 & $67.4(51.5 ; 82.7)$ & $4,384(3,892 ; 4,870)$ & $0.8(0.3 ; 1.7)$ & $121(80 ; 184)$ & $10.6(9.4 ; 11.8)$ & $16.4(14.6 ; 18.2)$ & 1.6 \\
\hline Percent reduction & $8 \%$ & $10 \%$ & $88 \%$ & $53 \%$ & $11 \%$ & $10 \%$ & \\
\hline \multicolumn{8}{|c|}{ Universal RV vaccination } \\
\hline RV1 & $40.6(30.1 ; 51.2)$ & $1,370(1,150 ; 1,650)$ & $0.4(0.2 ; 0.8)$ & $60(42 ; 81)$ & $3.4(28 ; 41)$ & $5.9(5.0 ; 6.9)$ & 15.2 \\
\hline Percent reduction & $45 \%$ & $72 \%$ & $94 \%$ & $77 \%$ & $71 \%$ & $67 \%$ & \\
\hline RV5 & $42.6(31.7 ; 53.6)$ & $1,440(1,210 ; 1,710)$ & $0.5(0.2 ; 0.9)$ & $66(45 ; 91)$ & $3.6(3.1 ; 4.3)$ & $6.3(5.3 ; 7.3)$ & 16.7 \\
\hline Percent reduction & $43 \%$ & $70 \%$ & $92 \%$ & $75 \%$ & $70 \%$ & $65 \%$ & \\
\hline
\end{tabular}

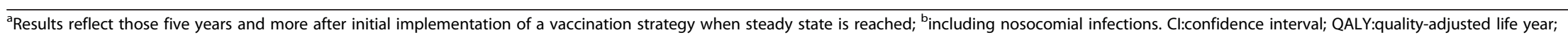
RV: rotavirus. 
million or $€ 1.6$ million (RV1 or RV5). Five hundred (RV1, 95\% CI: 420 to 590) or 490 (RV5, 95\% CI: 410 to 570) hospitalizations are avoided while the number of avoided fatal infections is similar to results for universal RV vaccination (5.8 cases, 95\% CI: 3.0 to 9.5). A total of 137 QALY's are gained.

As outcome results for either vaccine were almost identical, further analyses presented are based on RV1 vaccination with results for RV5 available in Additional file 1: Table S5.

Net healthcare costs (defined as vaccination costs minus healthcare savings) were compared for different scenarios (Figure 1). Undiscounted annual net healthcare costs of universal RV vaccination compared to no vaccination varied between $€ 3.7$ and $€ 9.6$ million, depending on assumptions about vaccine price, herd-immunity and vaccine coverage. Results of targeted vaccination versus no vaccination varied between net savings of $€ 0.1$ million up to maximum costs of $€ 0.5$ million. Comparing the free market vaccine price in both strategies resulted in a difference of $€ 16$ million annually ( $€ 16.9$ versus $€ 0.7$ million for universal and targeted vaccination, respectively).

Universal RV vaccination compared to no vaccination is unlikely to be cost-effective from the healthcare provider perspective at a willingness-to-pay threshold of €35,000/ QALY gained (Figure 2 and Additional file 1: Figure S2). Among the different scenarios analyzed for universal RV vaccination, the only cost-effective scenario included both herd immunity and caretaker QALY losses and assumed a vaccine price of €60/child (ICER: €21,309/QALY, 95\% CI: $11,079$ to 36,047$)$. Targeted RV vaccination is highly cost- effective in all scenarios tested. The best case scenario is dominant with net discounted mean savings of $€ 60,000$ and 67 QALY's gained compared to no vaccination. The maximum ICER for targeted vaccination is $€ 8,700$ /QALY when using the free market price (Figure 2). Moving from targeted vaccination to universal $\mathrm{RV}$ vaccination under base-case assumptions generates $€ 5.3$ million in mean incremental costs and 33 additional QALY's gained. The mean ICER for universal versus targeted vaccination is $€ 162,000 / \mathrm{QALY}$ using a healthcare provider perspective (Table 5). Outcome results from the societal perspective and analyses based on different discount rates are provided in Additional file 1: Table S6.

Cost-effectiveness was most sensitive to the estimated mortality rate. We, therefore, included a threshold analysis to identify the cut-off value of the parameter at which targeted vaccination would no longer be cost-effective. Targeted vaccination remained highly cost-effective up to a reduction of $90 \%$ in mortality rate, which translates to less than 1 RV death per year (Figure 3).

Choosing between competing strategies requires consideration of cost-effectiveness acceptability curves, which visualize the probability of cost-effectiveness dependent on the willingness-to-pay for health benefits. At a threshold of $€ 35,000 / \mathrm{QALY}$, we estimate the probability of cost-effectiveness of universal $\mathrm{RV}$ vaccination under base-case assumptions from the healthcare provider perspective to be $6 \%$, and $71 \%$ from a societal perspective (Figure 4). The probability of cost-effectiveness of targeted vaccination both at the $€ 35,000 / \mathrm{QALY}$ and $€ 20,000 / \mathrm{QALY}$ thresholds is $100 \%$ for both healthcare provider and societal perspectives.
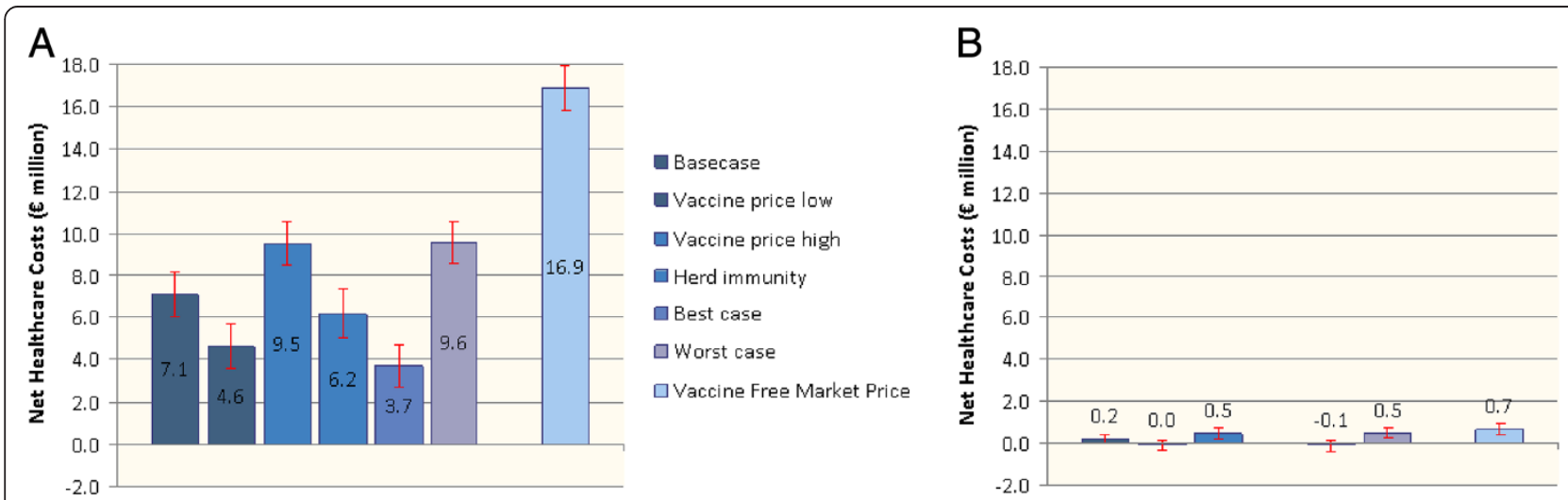

Figure 1 Comparison of annual net healthcare costs for RV vaccination strategies. Net undiscounted annual healthcare costs for universal (A) and targeted RV vaccination (B) compared to no vaccination under different assumptions and corresponding 95\% Cl. 'Basecase' represents results when the vaccine price per course is $€ 75$ per child, coverage is $88 \%$, and no herd immunity is present. 'Vaccine price low' and 'high' represent results for a vaccine price per course of $€ 60$ and $€ 95$ per vaccinated child, respectively. 'Herd immunity' includes protection of unvaccinated children. A scenario with herd immunity effects was not included for targeted vaccination. 'Best case' represents results from a low vaccine price, coverage of $97 \%$ and presence of herd immunity. 'Worst case' represents a high vaccine price, coverage of $65 \%$ and no herd immunity. Vaccine Free Market Price' shows results when the current listed vaccine price is used without any tender effects. Cl:confidence interval; RV: rotavirus. 


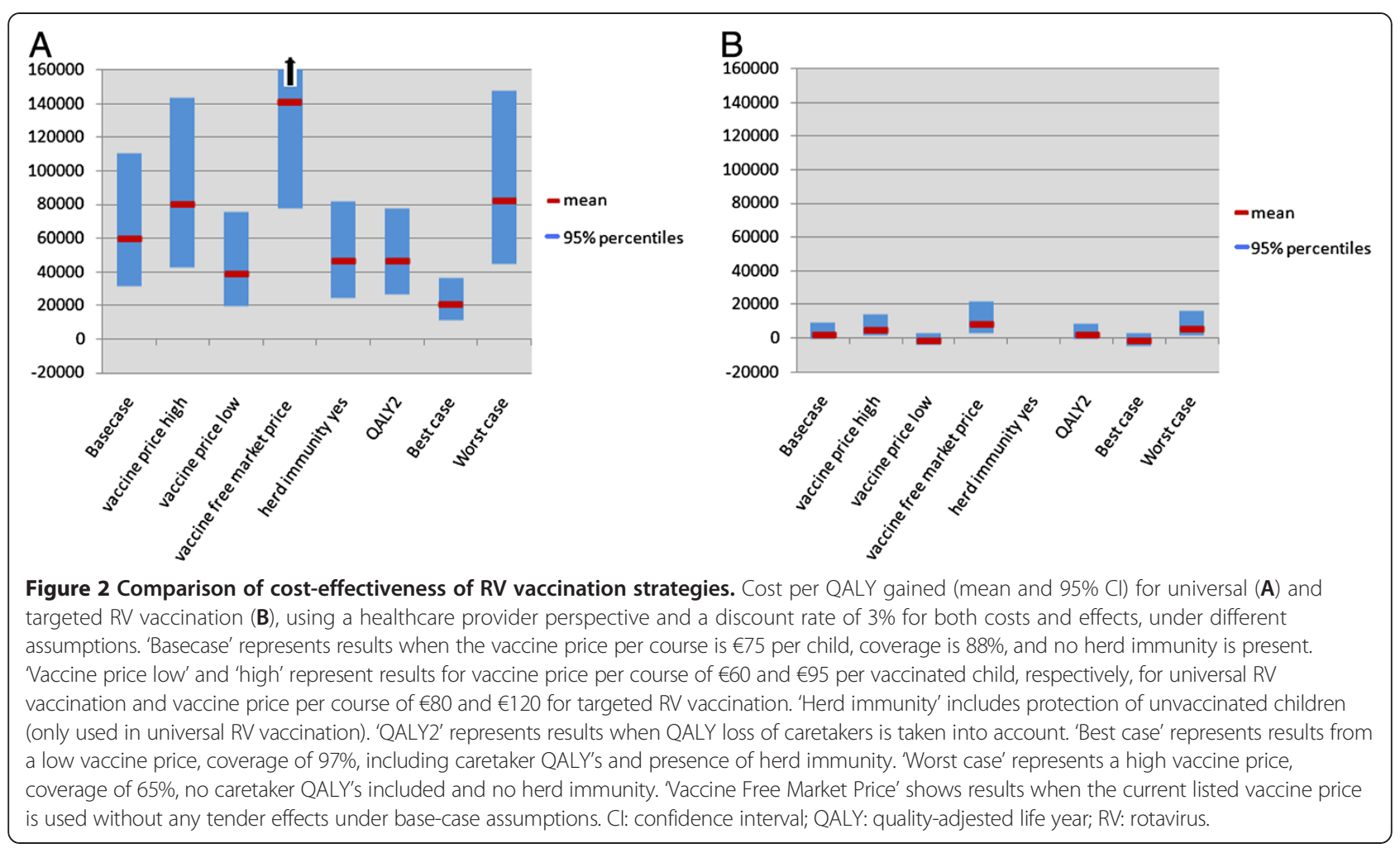

\section{Discussion}

Based on detailed Dutch epidemiological data analyzed in an age-structured, discrete-time event, stochastic multicohort model, we conclude that targeted RV vaccination of high-risk infants is highly cost-effective and potentially cost-saving in the Netherlands. Cost-effectiveness estimates were most sensitive to RV mortality rates, but targeted RV vaccination remained cost-effective when mortality would be $90 \%$ lower than observed.

In our analysis, universal RV vaccination was not considered cost-effective from the healthcare provider perspective and would only become cost-effective when herd-immunity and caretaker QALY losses were included and if vaccine prices would be at most $€ 60 /$ child. These results are in line with results from other European cost-effectiveness analyses that have used comparable methodology and QALY loss estimates for RVGE. Universal RV vaccination was not considered cost-effective from the healthcare provider perspective in Belgium, England and Wales, France, the Netherlands and Ireland, and was cost-effective in Finland only $[9,69]$. Our analysis demonstrated that universal RV vaccination could, however, be considered cost-effective from the societal perspective at the $€ 35,000 /$ QALY threshold. These findings differ somewhat from previous economic analyses of universal $\mathrm{RV}$ vaccination in the Netherlands $[9,10,45]$ which can be explained by the updated and more reliable parameter estimates used. Incidence and costs of RV hospitalizations in the Netherlands determined in our study are comparable to estimates from Germany, Finland and the UK and another

Table 5 Mean costs per different health outcome comparing different RV vaccination strategies under base-case assumptions (RV1) using a healthcare provider perspective

\begin{tabular}{llll}
\hline & Targeted versus no vaccination & Universal versus no vaccination & Universal versus targeted vaccination \\
\hline Costs $(\boldsymbol{\epsilon})^{\mathbf{a}}$ & & & 174 \\
per case avoided & 21 & 96,600 & 191 \\
per life year saved & 2,400 & $1.03^{\mathrm{b}}$ & 894,000 \\
per fatal case & $0.03^{\mathrm{b}}$ & 60,200 & $21.60^{\mathrm{b}}$ \\
per QALY gained & 2,600 & 162,000 \\
\hline
\end{tabular}

${ }^{\mathrm{a} A}$ discount rate of $3 \%$ was used for both costs and effects; ${ }^{\mathrm{b}} \in$ million. QALY, quality-adjusted life year; RV, rotavirus. 


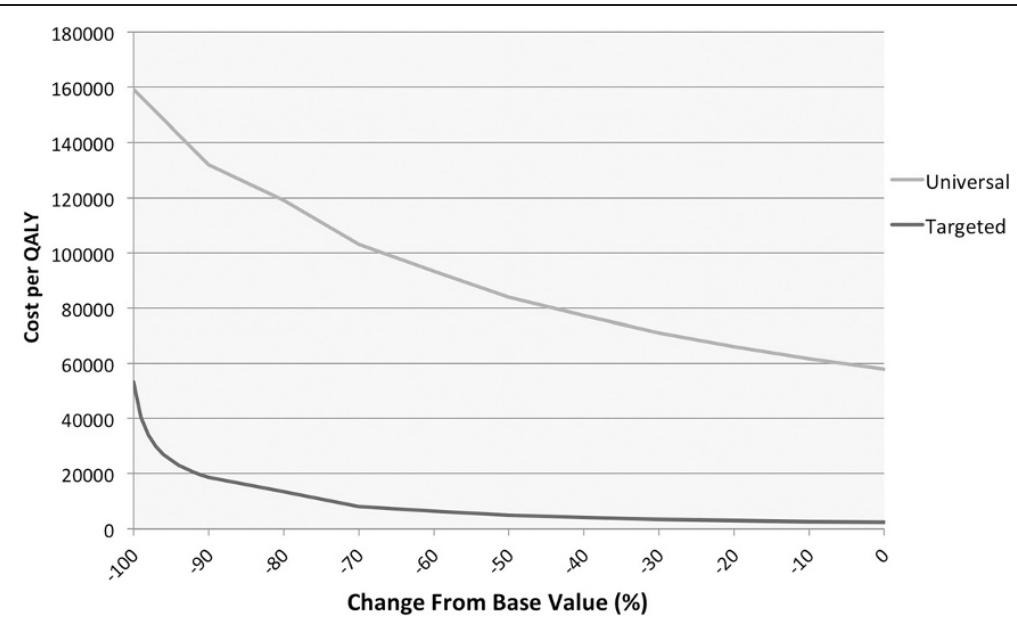

Figure 3 Mean cost per QALY gained by universal (grey line) and targeted (black line) RV vaccination, using a healthcare provider perspective and a discount rate of $3 \%$ for both costs and effects, as a function of change in mortality rate between $0 \%$ and $-100 \%$ (that is, no mortality at all) compared to baseline. QALY: quality-adjusted life year; RV: rotavirus.

recent Dutch observational study [65,70-72]. Previously, lower incidence and cost estimates were derived for the Netherlands by using indirect methods combining sentinel laboratory data and hospital discharge codes [73,74]. The accuracy and completeness of methods using discharge codes has been criticized and depends on local coding practices [75-77]. In addition, we could include recent estimates of parental work loss in children hospitalized for RV [51].

Our analysis did not account for potential costs and QALY losses associated with vaccination induced intussusception. Based on observed intussusception risks attributable to RV vaccination in different populations, 0 to 9 additional cases would occur each year in the Netherlands when universal RV vaccination is implemented [78-86]. Clearly, this could have a negative impact on cost-effectiveness, although overall effects may be small. Furthermore, the recent reports on an increased risk of intussusception after the first dose of $R V$ vaccine may raise concerns about exposing healthy children at low risk of RV-related complications to vaccination risks $[87,88]$.

Our study confirms that prematurity, LBW and congenital pathology are important risk factors for RV hospitalization and increased healthcare needs. Furthermore, we observed RV mortality exclusively among patients with any of these high-risk conditions. Although absolute numbers were low, similar observations in other European and US studies and the association between diarrhea-related mortality and birth weight confirm the existence of differential mortality risks [17,19,30-32]. Of note, in five out of seven patients who succumbed the underlying illness rather than RV was stated as the cause of death in deathrecords. Yet, in these patients RV caused a profound medical deterioration leading to premature death, as confirmed by expert review of case histories. These findings suggest

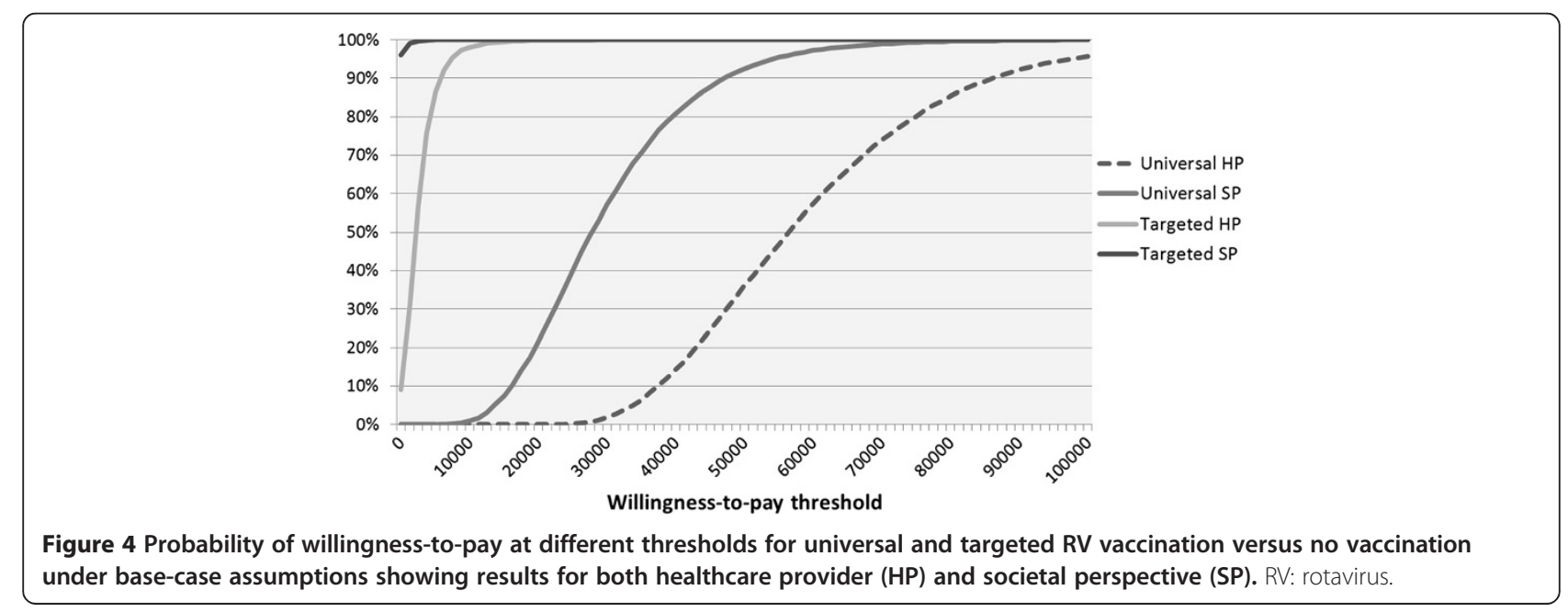


that among children with severe underlying conditions fatal RV disease is underreported.

Although limited data are available on vaccine safety and efficacy among high risk patients, protection provided by RV vaccine was comparable in premature and nonpremature infants without additional safety risk [89-91]. Current recommendations support RV vaccination in preterm infants and also in those with preexisting underlying disease, including gastrointestinal disease, in non-acute phases of illness [3,5,92]. Recently, it was shown that RV vaccination among short bowel patients is well tolerated [93].

Targeted RV vaccination does not offer the potential benefits of herd-protection, which has been described after implementation of universal RV vaccination. Observed effects among unvaccinated individuals ranged from 0 to $72 \%$ with substantial differences between consecutive years and effects declining with increasing age $[46,58,59]$. As severe RVGE occurs mainly in those $<5$ years old, herdimmunity could be a transient effect post-implementation, which disappears when coverage rates among this agegroup approach $100 \%$. Therefore, herd-immunity effects on the population level are difficult to predict [47]. Continued surveillance may provide more insights in coming years.

Naturally, our findings and conclusions may not hold for countries with high RV mortality among the general infant population and with higher RVGE incidences. In such countries universal RV vaccination remains the recommended approach.

\section{Conclusions}

Universal RV vaccination is the preferred strategy to decrease the high disease burden among young children caused by RV in European countries and elsewhere, but is probably not cost-effective from the healthcare provider perspective. Targeted RV vaccination of high-risk infants is highly cost-effective and can nearly eliminate RV mortality in developed countries with very limited impact on healthcare budgets. We, therefore, encourage policy makers in countries without $R V$ vaccination programs to prioritize $R V$ vaccination for high-risk infants.

\section{Additional file}

Additional file 1: Description nested case-control study: methods and results. Additional tables with cost calculations and model results.

\section{Abbreviations}

Cl: confidence interval; GA: gestational age; GE: gastroenteritis; ICER: incremental cost-effectiveness ratio; LBW: low-birth weight; QALY: quality-adjusted life year; RR: risk ratio; RV: rotavirus; YLL: years of life lost.

\section{Competing interests}

All authors declare they have no competing interests.

\section{Authors' contributions}

PB-V coordinated the study project. She was involved in study design and execution, data collection, analysis and interpretation and manuscript writing. MM was involved in data analysis and interpretation and assisted in drafting the manuscript. $\mathrm{NH}, \mathrm{MF}, \mathrm{MvH}, \mathrm{LW}$ and $\mathrm{WdW}$ were involved in onsite study execution and data collection. $\mathrm{NH}, \mathrm{MF}$ and $\mathrm{MvH}$ were also involved in data interpretation. MB supervised the study during all stages of the research process, was involved in data interpretation and assisted in drafting the manuscript. All authors have seen and approved the final version of the manuscript. PB-V and MM had full access to all of the data in the study and take responsibility for the integrity of the data and the accuracy of the data analysis.

\section{Author details}

${ }^{1}$ Julius Center for Health Sciences and Primary Care, University Medical Center Utrecht, Huispostnummer STR.6.131, Postbus 85500, Utrecht 3508 GA, The Netherlands. '2Department of Pediatrics, Spaarne Hospital, Postbus 770, Hoofddorp 2130 AT, The Netherlands. ${ }^{3}$ Department of Pediatrics, Sint-Franciscus Hospital, Postbus 10900, Rotterdam 3004 BA, The Netherlands. ${ }^{4}$ Department of Pediatrics, Kennemer Hospital, Postbus 417, Haarlem 2000 AK, The Netherlands. 'Department of Pediatrics, Diakonessen Hospital, Postbus 80250, Utrecht 3508 TG, The Netherlands.

Received: 5 October 2012 Accepted: 9 April 2013

Published: 26 April 2013

\section{References}

1. Cortes JE, Curns AT, Tate JE, Cortese MM, Patel MM, Zhou F, Parashar UD: Rotavirus vaccine and health care utilization for diarrhea in U.S. children. N Engl J Med 2011, 365:1108-1117.

2. Richardson V, Parashar U, Patel M: Childhood diarrhea deaths after rotavirus vaccination in Mexico. N Engl J Med 2011, 365:772-773.

3. National Advisory Committee on Immunization (NACl): Updated statement on the use of rotavirus vaccines. Can Commun Dis Rep 2010, 36:4. Advisory Committee Statement (ACS).

4. Committee on Infectious Diseases: Prevention of rotavirus disease: updated guidelines for use of rotavirus vaccine. Pediatrics 2009, 123:1412-1420.

5. Cortese MM, Parashar UD: Prevention of rotavirus gastroenteritis among infants and children: recommendations of the Advisory Committee on Immunization Practices (ACIP). MMWR Recomm Rep 2009, 58:1-25.

6. Vesikari T, Van Damme P, Giaquinto C, Gray J, Mrukowicz J, Dagan R, Guarino A, Szajewska H, Usonis V: Expert Working Group, European Society for Paediatric Infectious Diseases, European Society for Paediatric Gastroenterology, Hepatology, and Nutrition: European Society for Paediatric Infectious Diseases/European Society for Paediatric Gastroenterology, Hepatology, and Nutrition, Evidence-Based Recommendations for Rotavirus Vaccination in Europe: Executive Summary. J Pediatr Gastroenterol Nutr 2008, 46:615-618.

7. WHO: Rotavirus Vaccines: an update. WHO Weekly epidemiological record 2009, Report No: 51-52.

8. Widdowson MA, Meltzer MI, Zhang X, Bresee JS, Parashar UD, Glass RI: Cost-effectiveness and potential impact of rotavirus vaccination in the United States. Pediatrics 2007, 119:684-697.

9. Jit M, Mangen MJ, Melliez H, Yazdanpanah Y, Bilcke J, Salo H, Edmunds WJ, Beutels P: An update to "The cost-effectiveness of rotavirus vaccination: comparative analyses for five European countries and transferability in Europe". Vaccine 2010, 28:7457-7459.

10. Rozenbaum MH, Mangen MJ, Giaquinto C, Wilschut JC, Hak E, Postma MJ: Cost-effectiveness of rotavirus vaccination in the Netherlands; the results of a consensus model. BMC Public Health 2011, 11:462.

11. Bilcke J, Beutels P: Reviewing the cost effectiveness of rotavirus vaccination: the importance of uncertainty in the choice of data sources. Pharmacoeconomics 2009, 27:281-297.

12. Patel MM: Rotavirus vaccination programmes. BMJ 2012, 345:e5286.

13. Le Saux N, Bettinger J, Halperin S, Vaudry W, Scheifele D: Hospital Acquired Rotavirus Infections: Substantial Disease Burden in Canadian Pediatric Hospitals. Florence, Italy: Excellence in Pediatrics; 2009.

14. Johansen K, Bennet R, Bondesson K, Eriksson M, Hedlund KO, De Verdier KK, Uhnoo I, Svensson L: Incidence and estimates of the disease burden of rotavirus in Sweden. Acta Paediatr Suppl 1999, 88:20-23. 
15. Waisbourd-Zinman O, Ben-Ziony S, Solter E, Scherf E, Samra Z, Ashkenazi S: Hospitalizations for nosocomial rotavirus gastroenteritis in a tertiary pediatric center: A 4-year prospective study. Am J Infect Control 2009, 37:465-469.

16. Verhagen P, Moore D, Manges A, Quach C: Nosocomial rotavirus gastroenteritis in a Canadian paediatric hospital: incidence, disease burden and patients affected. J Hosp Infect 2011, 79:59-63.

17. Wildi-Runge S, Allemann S, Schaad U, Heininger U: A 4-year study on clinical characteristics of children hospitalized with rotavirus gastroenteritis. Eur J Pediatr 2009, 168:1343-1348.

18. Le Saux N, Bettinger JA, Halperin SA, Vaudry W, Scheifele DW: Substanital morbidity for hospitalized children with community acquired rotavirus infections: 2005-2007 IMPAct Surveillance in Canadian hospitals. Pediatr Infect Dis J 2010, 29:879-882.

19. Johansen K, Hedlund KO, Zweygberg-Wirgart B, Bennet R: Complications attributable to rotavirus-induced diarrhoea in a Swedish paediatric population: Report from an 11-year surveillance. Scand J Infect Dis 2008, 40:958-964.

20. Ford-Jones EL, Wang E, Petric M, Corey P, Moineddin R, Fearon M: Hospitalization for community-acquired, rotavirus-associated diarrhea: a prospective, longitudinal, population-based study during the seasonal outbreak, The Greater Toronto Area/Peel Region PRESI Study Group. Pediatric Rotavirus Epidemiology Study for Immunization. Arch Pediatr Adolesc Med 2000, 154:578-585

21. Chang HG, Glass Rl, Smith PF, Cicirello HG, Holman RC, Morse DL: Disease burden and risk factors for hospitalizations associated with rotavirus infection among children in New York State, 1989 through 2000. Pediatr Infect Dis J 2003, 22:808-814.

22. Dennehy $\mathrm{PH}$, Cortese MM, Bégué RE, Jaeger $J \mathrm{~L}$, Roberts NE, Zhang $\mathrm{R}$, Rhodes P, Gentsch J, Ward R, Bernstein DI, Vitek C, Bresee JS, Staat MA: A case-control study to determine risk factors for hospitalization for rotavirus gastroenteritis in U.S. children. Pediatr Infect Dis J 2006, 25:12.

23. Herruzo R, Omeñaca F, Garcia S, Diez J, Sanchez-Fauquier A: Identification of risk factors associated with nosocomial infection by rotavirus P4G2, in a neonatal unit of a tertiary-care hospital. Clin Microbiol Infect 2009, 15:280-285.

24. Newman RD, Grupp-Phelan J, Shay DK, Davis RL: Perinatal risk factors for infant hospitalization with viral gastroenteritis. Pediatrics 1999, 103:E3.

25. Rotbart HA, Nelson WL, Glode MP, Triffon TC, Kogut SJ, Yolken RH, Hernandez JA, Levin MJ: Neonatal rotavirus-associated necrotizing enterocolitis: case control study and prospective surveillance during an outbreak. J Pediatr 1988, 112:87-93.

26. Sharma R, Garrison RD, Tepas JJ III, Mollitt DL, Pieper P, Hudak ML, Bradshaw JA, Stevens G, Premachandra BR: Rotavirus-associated necrotizing enterocolitis: an insight into a potentially preventable disease? J Pediatr Surg 2004, 39:453-457.

27. Boccia D, Stolfi I, Lana S, Moro ML: Nosocomial necrotising enterocolitis outbreaks: epidemiology and control measures. Eur J Pediatr 2001, 160:385-391.

28. Bagci S, Eis-Hubinger AM, Yassin AF, Simon A, Bartmann P, Franz AR, Mueller $A$ : Clinical characteristics of viral intestinal infection in preterm and term neonates. Eur J Clin Microbiol Infect Dis 2010, 29:1079-1084.

29. Verboon-Maciolek MA, Truttmann AC, Groenendaal F, Skranes J, Dollner H, Hunt RW, Hayman M, Diepersloot RJ, van Loon AM, de Vries LS: Development of cystic periventricular leukomalacia in newborn infants after rotavirus infection. J Pediatr 2012, 160:165-168.

30. Desai R, Esposito DH, Lees C, Goodin K, Harris M, Blostein J, Parashar UD: Rotavirus-coded deaths in children, United States, 1999 to 2007. Pediatr Infect Dis J 2011, 30:986-988.

31. Parashar UD, Kilgore PE, Holman RC, Clarke MJ, Bresee JS, Glass RI: Diarrheal mortality in US infants: influence of birth weight on risk factors for death. Arch Pediatr Adolesc Med 1998, 152:47-51.

32. Mehal JM, Esposito DH, Holman RC, Tate JE, Callinan LS, Parashar UD: Risk factors for diarrhea-associated infant mortality in the United States, 2005 to 2007. Pediatr Infect Dis J 2012, 31:717-721.

33. Bruijning-Verhagen $P$, Sankatsing $V$, Kunst $A$, van den Born $C$, Bleeker $E$ Thijsen S, ljzerman EP, van der Velden VH, Bonten MJ: Rotavirus related hospitalizations are responsible for high seasonal peaks in all-cause pediatric hospitalizations. Pediatr Infect Dis J 2012, 31:e244-e249.

34. Feudtner C, Hays RM, Haynes G, Geyer JR, Neff JM, Koepsell TD: Deaths attributed to pediatric complex chronic conditions: national trends and implications for supportive care services. Pediatrics 2001, 107:e99.
35. Simon TD, Berry J, Feudtner C, Stone BL, Sheng X, Bratton SL, Dean JM, Srivastava R: Children with complex chronic conditions in inpatient hospital settings in the United States. Pediatrics 2010, 126:647-655.

36. Berry JG, Hall DE, Kuo DZ, Cohen E, Agrawal R, Feudtner C, Hall M, Kueser J, Kaplan W, Neff J: Hospital utilization and characteristics of patients experiencing recurrent readmissions within children's hospitals. JAMA 2011, 305:682-690.

37. Eurocat Noord Nederland: Algemene cijfers tabel 1,2,3 en 4. Eurocat Nederland 2011, Available from: http://www.rug.nl/umcg/faculteit/ disciplinegroepen/MedischeGenetica/Eurocat/tabellen; Accessed: 1 April 2012.

38. Stichting Perinatale Registratie Nederland (PRN): Perinatale Zorg in Nederland. 2008, 1-149. Available from: http://www.perinatreg.nl/ jaarboeken_zorg_in_nederland?noCache=365;1332865370.

39. Hakkart-van Roijen L, Tan S, Bouwmans C: Methoden en standaard kostprijzen voor economische evaluaties in de gezondheidszorg. [Methods and standard cost prices for economic evaluations in healthcare]. Version 2010. Diemen, The Netherlands: College van Zorgverzekeringen; 2011.

40. Indeling tarieflijst instellingen 2011 [Charges for healthcare institutions 2011]. Nederlandse Zorgautoriteit: Bijlage 2; 2011. Report No.: BR_CU_2015.

41. Hubben G, Bootsma M, Luteijn M, Glynn D, Bishai D, Bonten M, Postma M: Modelling the costs and effects of selective and universal hospital admission screening for methicillin-resistant Staphylococcus aureus. PLoS One 2011, 6:e14783.

42. Lumley T: Analysis of complex survey samples. Journal of Statistical Software 2004, 9:1-19.

43. Thompson SG, Barber JA: How should cost data in pragmatic randomised trials be analysed? BMJ 2000, 320:1197-1200.

44. Addition of severe combined immunodeficiency as a contraindication for administration of rotavirus vaccine. MMWR Morb Mortal Wkly Rep 2011, 59:687-688.

45. Mangen MJ, van Duynhoven YT, Vennema H, Van PW, Havelaar AH, De Melker HE: Is it cost-effective to introduce rotavirus vaccination in the Dutch national immunization program? Vaccine 2010, 28:2624-2635.

46. Zickafoose JS, Benneyworth BD, Riebschleger MP, Espinosa CM, Davis MM: Hospitalizations for intussusception before and after the reintroduction of rotavirus vaccine in the United States. Arch Pediatr Adolesc Med 2012, 166:350-355.

47. Tate JE, Steele AD, Bines JE, Zuber PL, Parashar UD: Research priorities regarding rotavirus vaccine and intussusception: a meeting summary. Vaccine 2012, 30:A179-A184.

48. Yen C, Tate JE, Steiner CA, Cortese MM, Patel MM, Parashar UD: Trends in intussusception hospitalizations among US infants before and after implementation of the rotavirus vaccination program, 2000-2009. J Infect Dis 2012, 206:41-48.

49. Van der Wielen M, Van Damme P: Pentavalent human-bovine (WC3) reassortant rotavirus vaccine in special populations: a review of data from the Rotavirus Efficacy and Safety Trial. Eur J Clin Microbiol Infect Dis 2008, 27:495-501.

50. Goveia MG, Rodriguez ZM, Dallas MJ, Itzler RF, Boslego JW, Heaton PM, DiNubile MJ: REST Study Team: Safety and efficacy of the pentavalent human-bovine (WC3) reassortant rotavirus vaccine in healthy premature infants. Pediatr Infect Dis J 2007, 26:1099-1104.

51. Tilson L, Jit M, Schmitz S, Walsh C, Garvey P, McKeown P, Barry M: Costeffectiveness of universal rotavirus vaccination in reducing rotavirus gastroenteritis in Ireland. Vaccine 2011, 29:7463-7473.

52. Friesema I, Lugnér A, van Duynhoven YT: GEops Working Group: Costs of gastroenteritis in the Netherlands, with special attention for severe cases. Eur J Clin Microbiol Infect Dis 2012, 31:1895-1900.

53. Desai R, Curns AT, Steiner CA, Tate JE, Patel MM, Parashar UD: All-cause gastroenteritis and rotavirus-coded hospitalizations among US children, 2000-2009. Clin Infect Dis 2012, 55:e28-e34.

54. Pitzer VE, Atkins KE, de Blasio BF, Van ET, Atchison CJ, Harris JP, Shim E, Galvani AP, Edmunds WJ, Viboud C, Patel MM, Grenfell BT, Parashar UD, Lopman BA: Direct and indirect effects of rotavirus vaccination: comparing predictions from transmission dynamic models. PLoS One 2012, 7:e42320.

55. Centraal Bureau voor de Statistiek: Bevolking; Kerncijfers. Available from: http://statline.cbs.nl; Accessed: 18 October 2011.

56. de Wit MA, Koopmans MP, Kortbeek LM, Wannet WJ, Vinje J, van Leusden F, Bartelds Al, van Duynhoven YT: Sensor, a population-based cohort study on gastroenteritis in the Netherlands: incidence and etiology. Am J Epidemiol 2001, 154:666-674 
57. Fang AY, Tingay DG: Early observations in the use of oral rotavirus vaccination in infants with functional short gut syndrome. J Paediatr Child Health 2012, 48:512-516.

58. Vesikari T, Itzler R, Karvonen A, Korhonen T, Van DP, Behre U, Bona G, Gothefors L, Heaton PM, Dallas M, Goveia MG: RotaTeq, a pentavalent rotavirus vaccine: efficacy and safety among infants in Europe. Vaccine 2009, 28:345-351.

59. Vesikari T, Karvonen A, Ferrante SA, Ciarlet M: Efficacy of the pentavalent rotavirus vaccine, RotaTeq(R), in Finnish infants up to 3 years of age: the Finnish Extension Study. Eur J Pediatr 2010, 169:1379-1386

60. Vesikari T, Dennehy P, Matson D, Itzler R, Dallas M, Goveia M, DiNubile M, Heaton P, Lawrence J, Ciarlet M: Efficacy of Rotateq ${ }^{\oplus}$, the pentavalent rotavirus vaccine, between doses: potential benefits of early protection [abstract]. Arch Dis Child 2008, 93:pw 70.

61. Brisson $M$, Sénécal $M$, Drolet $M$, Mansi JA: Health-related quality of life lost to rotavirus-associated gastroenteritis in children and their parents: a Canadian prospective study. Pediatr Infect Dis J 2010, 29:73-75.

62. Brandhof WE, Wit GA, Wit MA, Duynhoven $Y T$ : Costs of gastroenteritis in the Netherlands. Epidemiol Infect 2004, 132:211-221.

63. de Wit MA, Koopmans MP, Kortbeek LM, van Leeuwen NJ, Bartelds Al, van Duynhoven YT: Gastroenteritis in sentinel general practices, The Netherlands. Emerg Infect Dis 2001, 7:82-91.

64. Vesikari T, Karvonen A, Prymula R, Schuster V, Tejedor JC, Cohen R, Meurice F, Han HH, Damaso S, Bouckenooghe A: Efficacy of human rotavirus vaccine against rotavirus gastroenteritis during the first 2 years of life in European infants: randomised, double-blind controlled study. Lancet 2007, 370:1757-1763.

65. Vesikari T, Dennehy P, Matson D: Efficay of Pentavalent Rotavirus Vaccine, RotaTeq, between Doses: Potential Benefits of Early Protection. Istanbul, Turkey: 8th International Rotavirus Symposium; 2008.

66. Lopman BA, Curns AT, Yen C, Parashar UD: Infant rotavirus vaccination may provide indirect protection to older children and adults in the United States. J Infect Dis 2011, 204:980-986.

67. Payne DC, Staat MA, Edwards KM, Szilagyi PG, Weinberg GA, Hall CB, Chappell J, Curns AT, Wikswo M, Tate JE, Lopman BA, Parashar UD: New Vaccine Surveillance Network (NVSN): Direct and indirect effects of rotavirus vaccination upon childhood hospitalizations in 3 US counties, 2006-2009. Clin Infect Dis 2011, 53:245-253

68. Macartney KK, Porwal M, Dalton D, Cripps T, Maldigri T, Isaacs D, Kesson A: Decline in rotavirus hospitalisations following introduction of Australia's national rotavirus immunisation programme. J Paediatr Child Health 2011, 47:266-270

69. Buttery JP, Lambert SB, Grimwood K, Nissen MD, Field EJ, Macartney KK, Akikusa JD, Kelly JJ, Kirkwood CD: Reduction in rotavirusassociated acute gastroenteritis following introduction of rotavirus vaccine into Australia's National Childhood vaccine schedule. Pediatr Infect Dis J 2011, 30:S25-S29.

70. Raes M, Strens D, Vergison A, Verghote M, Standaert B: Reduction in pediatric rotavirus-related hospitalizations after universal rotavirus vaccination in Belgium. Pediatr Infect Dis J 2011, 30:e120-e125.

71. Vesikari T, Karvonen A, Ferrante SA, Kuter BJ, Ciarlet M: Sustained efficacy of the pentavalent rotavirus vaccine, RV5, up to 3.1 years following the last dose of vaccine. Pediatr Infect Dis J 2010, 29:957-963.

72. Iturriza-Gómara M, Dallman T, Bányai K, Böttiger B, Buesa J, Diedrich S, Fiore L, Johansen K, Koopmans M, Korsun N, Koukou D, Kroneman A, László B, Lappalainen M, Maunula L, Marques AM, Matthijnssens J, Midgley S, Mladenova Z, Nawaz S, Poljsak-Prijatelj M, Pothier P, Ruggeri FM, Sanchez-Fauquier A, Steyer A, Sidaraviciute-Ivaskeviciene I, Syriopoulou V, Tran AN, Usonis V, VAN Ranst M, et al: Rotavirus genotypes co-circulating in Europe between 2006 and 2009 as determined by EuroRotaNet, a pan-European collaborative strain surveillance network. Epidemiol Infect 2011, 139:895-909.

73. Zeller M, Rahman M, Heylen E, De CS, De Vos S, Arijs I, Novo L, Verstappen N, Van Ranst M, Matthijnssens J: Rotavirus incidence and genotype distribution before and after national rotavirus vaccine introduction in Belgium. Vaccine 2010, 28:7507-7513.

74. Friesema $\mathrm{IH}$, de Boer RF, Duizer E, Kortbeek LM, Notermans DW, Norbruis $\mathrm{OF}$, Bezemer DD, van Heerbeek H, van Andel RN, van Enk JG, Fraaij PL, Koopmans MP, Kooistra-Smid AM, van Duynhoven YT: Etiology of acute gastroenteritis in children requiring hospitalization in the Netherlands. Eur J Clin Microbiol Infect Dis 2011, 31:405-415.

75. Tan-Torres Edejer T, Baltussen R, Adam T, Hutubessy R, Acharya A, Evans DB, Murray CJL: WHO Guide to Cost-effectiveness Analysis. Geneva: World Health Organization; 2003

76. Laupacis A, Feeny D, Detsky AS, Tugwell PX: How attractive does a new technology have to be to warrant adoption and utilization? Tentative guidelines for using clinical and economic evaluations. CMAJ 1992, 146:473-481.

77. Eichler HG, Kong SX, Gerth WC, Mavros P, Jonsson B: Use of cost-effectiveness analysis in health-care resource allocation decisionmaking: how are cost-effectiveness thresholds expected to emerge? Value Health 2004, 7:518-528.

78. Koch J, Wiese-Posselt M: Epidemiology of rotavirus infections in children less than 5 years of age: Germany, 2001-2008. Pediatr Infect Dis J 2011, 30:112-117.

79. Harris JP, Jit M, Cooper D, Edmunds WJ: Evaluating rotavirus vaccination in England and Wales part I, estimating the burden of disease. Vaccine 2007, 25:3962-3970.

80. Vesikari T, Rautanen T, Von Bonsdorff CH: Rotavirus gastroenteritis in Finland: burden of disease and epidemiological features. Acta Paediatr Suppl 1999, 88:24-30.

81. de Wit MA, Koopmans MP, van der Blij JF, van Duynhoven YT: Hospital admissons for rotavirus infection in the Netherlands. Clin Infect Dis 2000, 31:698-704.

82. van Pelt W, Notermans D, Mevius D, Vennema H, Koopmans M, van Duynhoven Y: Trends in gastro-enteritis van 1996-2006: Verdere toename van ziekenhuisopnames, maar stabiliserende sterfte. Infectieziektenbulletin 2008, 19:24-31.

83. Parashar UD, Holman RC, Clarke MJ, Bresee JS, Glass RI: Hospitalizations associated with rotavirus diarrhea in the United States, 1993 through 1995: surveillance based on the new ICD-9-CM rotavirus-specific diagnostic code. J Infect Dis 1998, 177:13-17.

84. Hsu VP, Staat MA, Roberts N, Thieman C, Bernstein DI, Bresee J, Glass RI, Parashar UD: Use of active surveillance to validate international classification of diseases code estimates of rotavirus hospitalizations in children. Pediatrics 2005, 115:78-82.

85. Matson DO, Staat MA, Azimi P, Itzler R, Bernstein DI, Ward RL, Dahiya R, DiNubile MJ, Barnes-Eley M, Berke T: Burden of rotavirus hospitalisations in young children in three paediatric hospitals in the United States determined by active surveillance compared to standard indirect methods. J Paediatr Child Health 2012, 48:698-704.

86. Belongia EA, Irving SA, Shui IM, Kulldorff M, Lewis E, Yin R, Lieu TA, Weintraub E, Yih WK, Li R, Baggs J: Vaccine Safety Datalink Investigation Group: Real-time surveillance to assess risk of intussusception and other adverse events after pentavalent, bovine-derived rotavirus vaccine. Pediatr Infect Dis J 2010, 29:1-5.

87. Buttery JP, Danchin MH, Lee KJ, Carlin JB, Mclntyre PB, Elliott EJ, Booy R, Bines JE: PAEDS/APSU Study Group: Intussusception following rotavirus vaccine administration: post-marketing surveillance in the National Immunization Program in Australia. Vaccine 2011, 29:3061-3066.

88. Geier DA, King PG, Sykes LK, Geier MR: The temporal relationship between RotaTeq immunization and intussusception adverse events in the Vaccine Adverse Event Reporting System (VAERS). Med Sci Monit 2012, 18:H12-H17.

89. Haber P, Patel M, Izurieta HS, Baggs J, Gargiullo P, Weintraub E, Cortese M, Braun MM, Belongia EA, Miller E, Ball R, Iskander J, Parashar UD: Postlicensure monitoring of intussusception after RotaTeq vaccination in the United States, February 1, 2006, to September 25, 2007. Pediatrics 2008, 121:1206-1212.

90. Loughlin J, Mast TC, Doherty MC, Wang FT, Wong J, Seeger JD: Postmarketing evaluation of the short-term safety of the pentavalent rotavirus vaccine. Pediatr Infect Dis J 2012, 31:292-296.

91. Patel MM, Lopez-Collada VR, Bulhoes MM, de Oliveira LH, Bautista MA Flannery B, Esparza-Aguilar M, Montenegro Renoiner El, Luna-Cruz ME, Sato HK, Hernández-Hernández Ldel C, Toledo-Cortina G, Cerón-Rodríguez M, Osnaya-Romero N, Martínez-Alcazar M, Aguinaga-Villasenor RG, PlascenciaHernández A, Fojaco-González F, Hernández-Peredo Rezk G, Gutierrez-Ramírez SF, Dorame-Castillo R, Tinajero-Pizano R, Mercado-Villegas B, Barbosa MR, Maluf EM, Ferreira LB, de Carvalho FM, dos Santos AR, Cesar ED, de Oliveira ME, et al: Intussusception risk and health benefits of rotavirus vaccination in Mexico and Brazil. N Engl J Med 2011, 364:2283-2292.

92. Shui IM, Baggs J, Patel M, Parashar UD, Rett M, Belongia EA, Hambidge SJ, Glanz JM, Klein NP, Weintraub E: Risk of intussusception following 
administration of a pentavalent rotavirus vaccine in US infants. JAMA 2012, 307:598-604.

93. Velazquez FR, Colindres RE, Grajales C, Hernandez MT, Mercadillo MG, Torres FJ, Cervantes-Apolinar M, DeAntonio-Suarez R, Ortega-Barria E, Blum M, Breuer T, Verstraeten T: Postmarketing surveillance of intussusception following mass introduction of the attenuated human rotavirus vaccine in Mexico. Pediatr Infect Dis J 2012, 31:736-744.

94. Omeñaca F, Sarlangue J, Szenborn L, Nogueira M, Suryakiran P, Smolenov IV, Han HH: ROTA-054 Study Group: Safety, reactogenicity and immunogenicity of human rotavirus vaccine in preterm European infants: a randomized phase Illb study. Pediatr Infect Dis J 2012, 31:487-493.

doi:10.1186/1741-7015-11-112

Cite this article as: Bruijning-Verhagen et al:: Targeted rotavirus vaccination of high-risk infants; a low cost and highly cost-effective alternative to universal vaccination. BMC Medicine 2013 11:112.

\section{Submit your next manuscript to BioMed Central and take full advantage of:}

- Convenient online submission

- Thorough peer review

- No space constraints or color figure charges

- Immediate publication on acceptance

- Inclusion in PubMed, CAS, Scopus and Google Scholar

- Research which is freely available for redistribution 